\title{
Design, Economic Competitiveness, and Profitability of a 2025 LNG Fueled Turboprop for the LNG Air Transportation System
}

\author{
Jonathan M. Gibbs ${ }^{1}$, Bjoern Nagel. ${ }^{2}$ \\ DLR Institute for Air Transport Systems, Blohmstr 20. Hamburg, Germany 21073
}

\begin{abstract}
This paper describes the technical characteristics, lifecycle emissions and economic competitiveness of a hypothetical liquid natural gas (LNG) powered turboprop when introduced into a market place with both existing turboprops and potential competitive responses between 2025 and 2030 . Natural gas possesses vast potential to reduce emissions and improve operating costs in commercial aviation because it is cheaper and cleaner than jet fuel. The results show that LNG turboprop can completely robustly against current turboprops (ATR-72 and Bombardier Q400), the competitive responses of stretched derivative of the Q400 to 90 seats, and against discounted used version of current turboprops. Specifically, the LNG turboprop can achieve between a $9 \%$ and $15 \%$ operating cost advantage compared to current turboprops, $4.9 \%-8.9 \%$ against a stretch of the Q400 turboprop, and, a 3\%-11\% advantage against existing turboprops sold or leased at steep discounts. The program is shown to be profitable and yield a positive internal rate of return on invested capital between $9 \%$ and $17 \%$ if market share levels between $47 \%$ and $75 \%$ are achieved.
\end{abstract}

\section{Nomenclature}

$\begin{array}{ll}\text { ARJ } & =\text { Advanced Regional Jet } \\ A T R & =\text { Avions de transport regional } \\ L N G & =\text { Liquid Natural Gas } \\ H A L & =\text { Hindustan Aeronautics Limited }\end{array}$

\section{Introduction}

T NG is a cryogenic fuel that has the potential be used as an aviation fuel. It is attractive from both an economic Lstandpoint and a lifecycle emissions standpoint but has technical difference that require an all new fuselage and thus new aircraft design. The 90 seat turbroprop market is an early adoption candidate due to its recently announced availability of new engines and because 4 out of the 5 potential entrants require a new aircraft design. This paper will examine the economic implications of the LNG's fuel cost and new aircraft design on market share, and other competitive forces that could impact the success of an LNG turboprop program.

\section{Market}

There is currently a projected market for $1,340^{1}$ turboprop aircraft with 90 seats over the next 20 years worth approximately $\$ 26.52$ billion at likely final aircraft acquisition prices. 90 seat LNG turboprop aircraft will consume approximately 540,000 gallons of LNG (270,000 of equivalent jet fuel) per year worth \$0.4-\$0.5 million dollars per year per aircraft at US LNG industrial and retail prices. Storage and delivery infrastructure for LNG fuel would be required at 1 new airport for every LNG aircraft sold or roughly 670 airports at \$2 million per airport assuming a $50 \%$ market share ( $\$ 1.3$ billion). Turboprop customers are typically airlines that service short distance routes (under 300 nautical miles). A turboprop program will require the availability of lease financing. Leases account for half of all commercial aircraft financing and existing lessors may be hesitant to finance an aircraft that can initially use a limited infrastructure deployment because there is no guarantee that sufficient infrastructure will exist after the lease for the operator can liquidate the asset in a secondary market. A total of $\$ 13.25$ billion in lease financing would be required to fund $50 \%$ of the maximum possible number LNG turboprop aircraft purchases.

The market size for supersonic aircraft for over-water supersonic travel only is estimated at a total of 500 aircraft $^{2}$ worth approximately $\$ 22.5$ billion. Authorization of overland supersonic flight could be authorized if

\footnotetext{
${ }^{1}$ Researcher, DLR/TUHH Air Transport Systems Lab, Blohmstr. 20, Hamburg Germany

${ }^{2}$ Department Head-Aircraft Design, DLR/TUHH Air Transport Systems Lab, Blohmstr. 20, Hamburg Germany
} 
technical advances for low boom technology matured sufficiently. Supersonic aircraft would require 40 main airports world wide for overwater travel only - 630 fewer airports than the turboprop. It is unclear if lease financing for supersonic aircraft would be required--most charter airlines invest their own capital in aircraft but lease financing could make purchasing in LNG aircraft more attractive for the first customers.

\section{Turbo-Prop Characteristics and Technical Differences from using LNG}

Turboprop aircraft are known for their fuel efficiency, low external noise footprint, and versatility in using short runways. They also known for the their relatively slow speed, small cabins, cabin noise, lack of baggage compartments and a qualitative "less modern" feeling amongst customers. Turboprops have lost market share to regional jets within the last 15 years but still remain popular in many noise constrained areas, developing countries, and with cost conscious airline customers.

LNG aircraft require unique fuselage shapes to store the lower density LNG without an economically prohibitive drag penalty. As a consequence, existing fuselage shapes cannot be used but the wing parasite drag can be reduced with thinner airfoils because no jet fuel needs to be stored inside. The unique fuselage shape can also be designed to increase passenger comfort and make the aircraft more competitive with regional jet cabin sizes. Changes in the wings and fuselage shape rule out the possibility introducing an LNG aircraft by making small modifications to existing aircraft however existing, engines can be used if the combustor is retrofitted to burn natural gas---a practice that commonly occurs when designing natural gas power generators from natural gas aircraft turbines.

The use of existing engines can remove up to $75 \%$ of the development cost of a new engine. The use of LNG has also been observed to prolong engine life and reduce maintenance costs by $15 \%$ due to the lower sulfur content of the fuel. The LNG is vaporized before entering the engine and combusted as a gas or literally, natural gas. The low temperature of LNG presents an opportunity to improve engine efficiency through cooling of inlet air and bleed air. It may be possible to exploit some of these cooling advantages with an existing engine but it is likely that a new engine will need to be developed for LNG propulsion to reach its full potential.

LNG's environmental qualities will make it an attractive option for environmentally conscious airlines and for airlines that must operating within a carbon tax and trading environment such as the European Union. LNG emits between $10 \%$ and $80 \%$ less carbon on a life cycle basis depending on the extraction source of natural gas. Additionally, at least $80 \%$ less sulfur, NOx, and particulate matter regardless of the extraction source. Turboprops also cruise at an altitude that does less harm to the environment then turbofan powered aircraft (jet engines). A turboprop LNG aircraft would easily be the "greenest" commercial aircraft in operation and would provide a compelling marketing platform for LNG and a positive response with regard to the authorization and use of LNG from policy makers that seek to reduce climate change and improve the environment.

\section{Background on Competing Turboprop Aircraft and Potential New Entrants}

Avions de transport regional (ATR) (Airbus's (50\%) \& Alenia Aermacchi's (50\%)) and Bombardier, occupy strong incumbent positions in the 80 seat turboprop market with the ATR-72 and the Dash-8 Q400 respectively. Both aircraft have sold well: Th ATR-72 averages 31.96 orders per year ${ }^{3}$, and the Dash-8 Q400's averages 32.27 orders per year ${ }^{4}$.

ATR aircraft is currently considering a new turboprop design. The cabin/fuselage for the ATR-72 is too narrow to stretch to 90 seats without the tail hitting the ground on takeoff. The requirement for a new fuselage design creates an opportunity for ATR to integrate LNG into an all-new design without the opportunity cost investing less in a stretched derivative. They have publically stated that development costs would total $\$ 2$ Billion but this would require ether shareholder approval from Airbus, or, engineering and financial resources from another source such as KAI who is also looking to partner. ATR has indicated a desire to move forward with a 90 seat turboprop but the Airbus CEO has effectively vetoed the plan in favor of keeping Airbus's development resources focused on the Airbus commercial jet aircraft. Alenia, the other shareholder has also expressed interest in buying out Airbus's share of ATR and developing the aircraft alone.

Bombardier can stretch their Q400 aircraft to 90 seats which would present a low cost alternative to any all new design and would not suffer a drag penalty because the cross section would remain narrower 4 abreast instead of the wider 5 abreast design suggested by ATR. The current Bombardier Q400 has a considerable speed advantage over the ATR which could translate into a competitive advantage if it could be offered at the lower cost of a derivative aircraft. The current Q400 has also been configured seat 86 passengers in a single class configuration--much closer 
to the 90 seats that the market has called for which may negate the need for a derivate aircraft all together. Bombardier has been in talks with the South Korean Aerospace Industries to possibly co-develop a 90 seat turboprop as late as 2012 but these talks seem to have faltered. Currently Bombardier seems to commit all of its development resources to its $\mathrm{C}$-series regional aircraft which are similar in size but come with new engine technology and can be stretched to compete with single aisle jet aircraft from Boeing and Airbus. Several regional airlines have placed orders for the $\mathrm{C}$-series which could cut into the market share of any new turboprop developed by Bombardier.

New entrant turboprop aircraft from state backed entities are in varying stages of development. The AVIC MA700 program was formally launched by China in Q4 2013 and is currently accepting orders for an entry into service date of 2018. Turboprops may be especially attractive to China because they can help reduce air pollution. Orders form the MA700 are expected to come primarily from "developing countries in Asia and Africa". The HAL Regional Transport Aircraft from India is in development for both a turboprop and a regional jet but little is known about its progress. New entrant programs from developing countries have notoriously longer lead times than programs from established companies but they do tend to be sold at lower prices.

Regional jets have seen growth that has provided large windfalls for incumbent manufacturers Embraer and Bombardier, as well as new entrants from Russia's Sukohi, China's ARJ, and Mitsubishi. Regional Jets are less fuel efficient that turboprops but have been adopted more rapidly: 2435 regional jet orders since 19941306 ATR's, 1129 Dash 8's vs. 2689 regionial jets since 2001: E jet 1012, CRJ 1677.

\section{LNG Aircraft Eco System}

Creating both of the fuel and the aircraft markets will require launching a compelling LNG aircraft program and the presence of a supporting eco system of financing, maintenance, and fueling infrastructure. The creation of the supporting eco-system can be handled by existing third parties that currently provide the same functions for jetfueled aircraft. The maximum amounts of capital that can be committed to each part of the eco system and the likely profit margins are shown in

Figure 1. It is important to emphasize that while each element in the eco system needs to exist for market to be created, new capital may not be necessary as some elements can be converted by their existing operators with little to no additional capital at all. However, the figure does show the potential areas and additional profit margins can be attained if there is a desire to make investments and own assets beyond the aircraft program itself.

Figure 1. The required elements LNG Aircraft Eco System, maximum potential capital requirements and anticipated profit margins

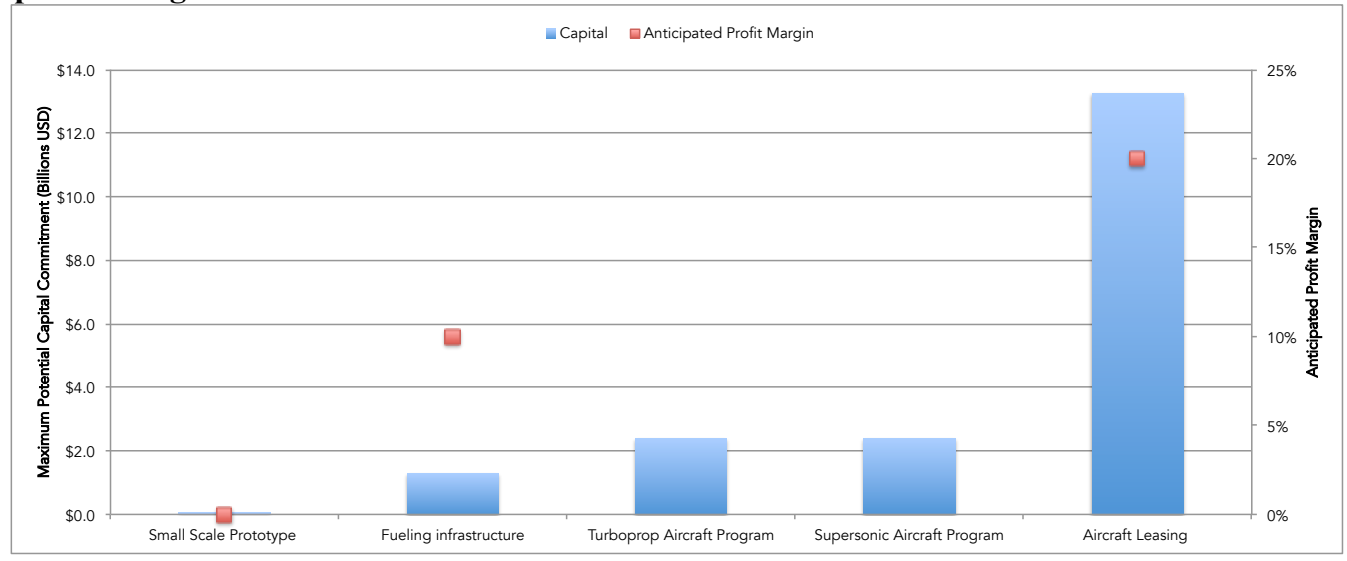

At a minimum, a small scale prototype, LNG fueling infrastructure, and aircraft financing (aircraft leasing) will also be required to create and sustain the LNG aircraft and fuel markets. A small scale prototype and intellectual property protection would cost $\$ 5$ - $\$ 15$ million USD and typically have a $0 \%$ profit margin unless the intellectual property is licensed or the company is acquired for its intellectual property. For this reason, prototypes are typically funded by public entities such as NASA, and DLR, or, with internal R\&D funds of an established company. There is enough LNG extraction and liquefaction capacity available to service the LNG aircraft market. However, the last 
mile of fueling infrastructure, or, infrastructure that brings LNG to airports is not yet in place in most places around the world. For small scale aircraft $(<10,000$ gallons of $L N G$ per airplane), the last mile of infrastructure can be installed for $\$ 1.7$ million to $\$ 2$ million USD per airport, or \$1.3 billion USD for all of 670 airports that are serviced by the LNG turboprop market. This infrastructure would consist of off site storage of 10,000-20,000 gallon LNG tanks and $1 \mathrm{LNG}$ refueling tanker to bring LNG to the airport for each aircraft. We assume a profit margin of $10 \%$ for this service with the final retail delivery cost being $50 \%$ less than the equivalent amount of jet fuel for the same mission. Lastly, aircraft leasing required to finance up to $50 \%$ of commercial LNG turboprop purchases (the maximum amount we think would be needed) is $\$ 13.25$ billion USD. Leasing has by far the largest potential capital investment but also has consistently high profit margins at $20 \%$. There are as would be expected, several highly profitable leasing companies that are well capitalized, but it is unclear if they will finance aircraft LNG aircraft before enough fueling infrastructure is in place to create a large secondary market to liquidate the aircraft after each lease expires.

\section{LNG Infrastructure}

New permanent airport infrastructure can be a substantial economic barrier to entry for any alternative fuel and/or transportation concept. Airport infrastructure upgrades for the A380 alone totaled \$927 million USD for 18 US airports for an average of $\$ 51$ million USD per airport and a minimum of $\$ 2.3$ million USD for the Tampa International airport. These infrastructure changes included new runways, taxiways and gates ${ }^{5}$. LNG however does not require permanent airport infrastructure to service airport or investments on the scale of the average A380 US airport investment.

LNG quantities under 10,000 gallons can be delivered to an aircraft without any permanent airport infrastructure investments - well within fully refueling a 90 seat turboprop. It is possible to add offsite infrastructure consisting of a storage tank and a delivery truck for approximately $\$ 1.7-\$ 2$ million USD per airport. Under this concept, pilots would be able to make their fuel requests 30 minutes before takeoff in order to insure delivery and consideration of the latest weather updates. A total of 1529 airports currently receive commercial aircraft service. The maximum cost for adding LNG infrastructure every possible airport in the world would total approximately $\$ 3$ billion USD. In reality, there is existing LNG infrastructure both for marine and ground transportation use that can also be used for airports. Additionally, commercial airports in close proximity such as Chicago O'Hare and Chicago Midway could share common LNG infrastructure.

\section{Development Cost Differences between LNG Aircraft and Jet A aircraft}

LNG quantities under 10,000 gallons can be delivered to an aircraft without any permanent airport infrastructure investments-well within fully refueling a 90 seat turboprop. It is possible to add offsite infrastructure consisting of a storage tank and a delivery truck for approximately $\$ 1.7-\$ 2$ million USD per airport. Under this concept, pilots would be able to make their fuel requests 30 minutes before takeoff in order to insure delivery and consideration of the latest weather updates. A total of 1529 airports currently receive commercial aircraft service. The maximum cost for adding LNG infrastructure every possible airport in the world would total approximately $\$ 3$ billion USD. In reality, there is existing LNG infrastructure both for marine and ground transportation use that can also be used for airports. Additionally, commercial airports in close proximity such as Chicago O'Hare and Chicago Midway could share common LNG infrastructure.

From a research and development standpoint, the technical differences between Jet-A and LNG aircraft are mainly in the fuselage which must be of an alternate shape to store the LNG, and, the wing which no longer contains LNG. A new engine development is not required, but the engine combustor needs to be modified to burn natural gas. The changes in development cost are calculated using the Markish model ${ }^{6}$. The Markish model takes as an input, the percentage of increased or decreased development efforts relative to the original development effort for major subsystems and then computes the new development cost based on historical ratios of each subsystem development cost, and an initial total cost computed by the Raymer-Dapca IV model ${ }^{7}$. The estimated percentage development cost changes and the final R\&D cost difference vs. the baseline are listed in Table 1. 
Table 1: LNG Aircraft Estimated Development Cost Differences

\begin{tabular}{|c|c|c|c|c|c|c|c|c|}
\hline \multicolumn{7}{|c|}{$\begin{array}{l}\text { LNG Aircraft Sub-system Development Effort Percentage } \\
\text { of Jet A Subsystem Effort }\end{array}$} & \multirow{2}{*}{$\begin{array}{l}\text { LNG Turboprop } \\
\text { Estimated } \\
\text { Development } \\
\text { Cost (\$USD) }\end{array}$} & \multirow{2}{*}{$\begin{array}{l}\text { Baseline Jet A } \\
\text { Turboprop } \\
\text { development } \\
\text { cost (\$USD) }\end{array}$} \\
\hline Wing & Empennage & Fuselage & $\begin{array}{c}\text { Landing } \\
\text { Gear }\end{array}$ & $\begin{array}{c}\text { Installed } \\
\text { Engine }\end{array}$ & Systems & Payloads & & \\
\hline $90 \%$ & $100 \%$ & $125 \%$ & $100 \%$ & $25 \%$ & $110 \%$ & $100 \%$ & $\$ 2,442,156,174$ & $\$ 2,081,008,647$ \\
\hline
\end{tabular}

The estimated cost differences result in an approximately $17 \%$ cost increase vs. an equivalent Jet A development program. This cost difference is reflected in the operating cost difference from an increase in aircraft ownership and insurance cost. It must be balanced by decreases in fuel and maintenance costs in order to be economically competitive. Additional development cost differences result from an assumed increased use of composites in the LNG program in order to make the specialized fuselage shape. The model's predicted baseline cost of the Jet-A turboprop program is within $4 \%$ of the cost predicted by ATR in public statements ${ }^{3}$. However, it should be noted that a considerable amount of uncertainty is also present in these estimates that result from differences in actual vs. predicted engineering design choices, material selection, and how the engine development cost is accounted for. In our model, we assume that the Raymer model includes the development costs for a new engine, and that the LNG aircraft would only assume an additional $25 \%$ of those costs for the combustor modification. Nevertheless, these costs are a high level estimate which is needed to accurately compute the overall operating cost differences.

\section{Competition Aircraft Prices vs. Potential LNG Aircraft Prices}

LNG turboprop aircraft face a complex competitive landscape of two well established incumbents ATR and Bombardier, potential new entrants from state backed entities in China, India and South Korea, and from low cost regional jets with the same passenger capacity. Although both state backed entities and incumbent manufacturers have indicated some desire to enter the 1340 aircraft market for 90 seat turboprops, this analysis indicates that a maximum of 2 entrants will be profitable because $30-40 \%$ market share is required to break even on development and manufacturing costs (see profitability section). A graph showing the possible price range for an LNG 90 seat turboprop aircraft vs. incumbent aircraft and future regional jets is shown in Figure 2. 
Figure 2. Aircraft Acquisition prices per Available Passenger Seat

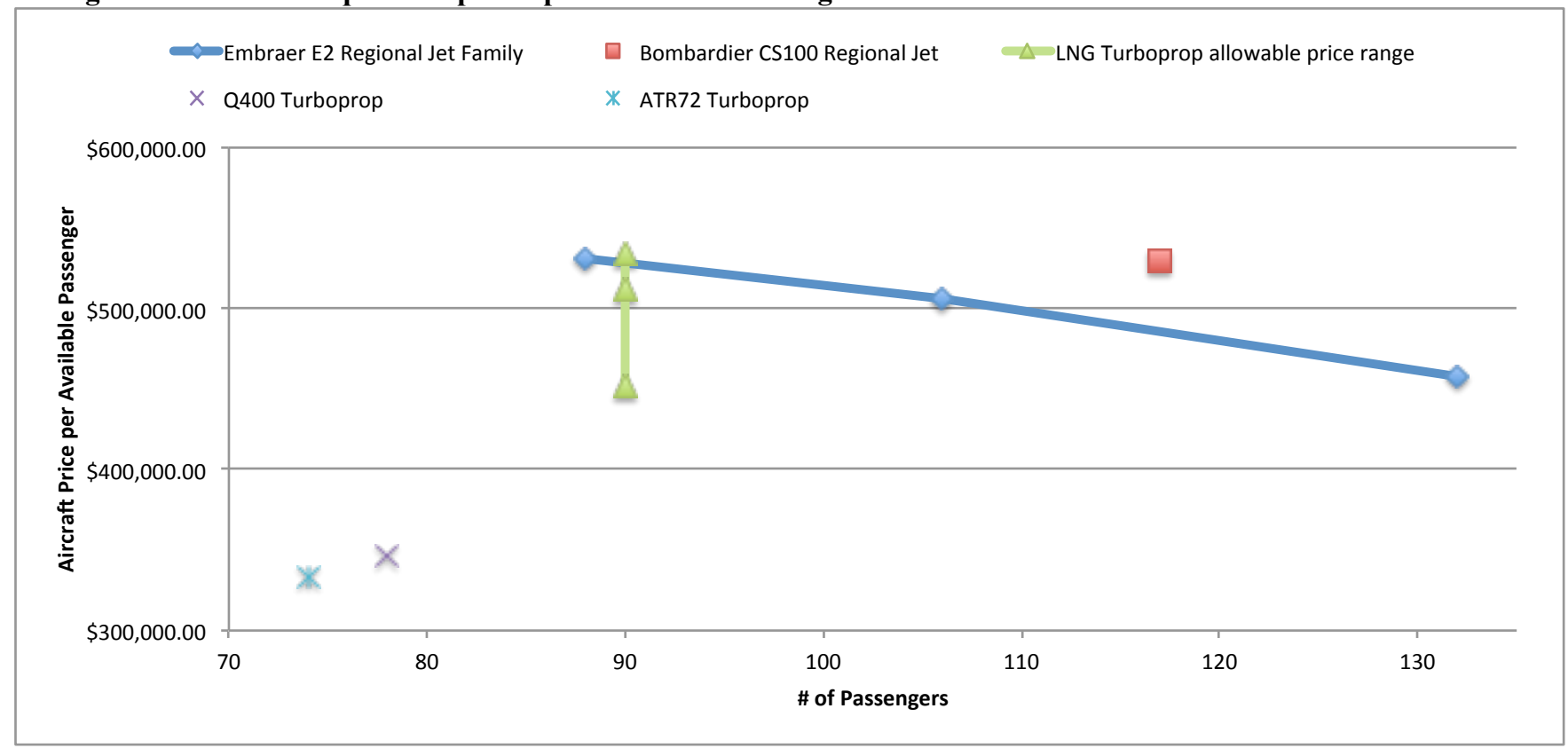

The prices for the LNG aircraft range reflect a range of allowable manufacturing profit margins. The lowest price/profit margin is an industry typical 50-50 split of the cost savings from using LNG between the airline and the manufacturer and comes out to a $5.7 \%$ manufacturing margin. The highest price represents the margin that will give airlines equal operating costs with a jet-fueled turboprop and comes out to a $25 \%$ margin for the manufacturer. A third price, a $20 \%$ margin, is shown for comparison purposes. In the range of potential margins, the LNG turboprop is priced above smaller incumbent turboprops (the Q-400 and ATR72) and close in range with future regional jets (the future Embraer E2- series and the future Bombardier CS100). However, in all of the LNG pricing scenarios, the LNG aircraft will have lower or equal overall operating costs than incumbent turboprops and future regional jets on all routes less than 300 nautical miles because the higher acquisition cost is mitigated by lower fuel and maintenance costs.

\section{Pricing Pressure from Competing Aircraft \& LNG Aircraft Cost Advantages}

It is important to note that operating and acquisition costs relative to new and existing aircraft are not a complete predictor of the competitive prowess and market performance of an aircraft. The switching costs for stocking new spare parts (including engines), and training must also be accounted for as well as the possible discounts that existing manufacturers can give. Aircraft lessors have noted that the new Bombardier CS100, a more fuel efficient third entrant in the market for single aisle turbofan aircraft is "hard to place" with airlines because lease rates of existing aircraft are less than half those of new aircraft that operating costs are mitigated by the additional infrastructure required for stocking spare parts ${ }^{8,9}$

"At the Istat Americas 2013 conference in Orlando, Fla., Udvar-Hazy told Aviation Week, "it is not a family of aircraft," and its better fuel burn will be offset by the infrastructure costs of supporting new avionics, engines and other systems. Moreover, lease rates for existing aircraft have dropped since the program's launch. "Today, you can get 6-7-yearold A319s at less than half the monthly rate of a new CSeries," he said. "So we have an aircraft that overall is not probably where it needs to be." And when it comes to campaigns for new aircraft, Airbus and Boeing have made it clear that they are willing to use pricing as a tool to keep Bombardier away from their customer base. Some airlines are prepared to purchase older technology if the pricing is right, as evidenced by the likely announcement next week of a Ryanair order for 200 Boeing 737 NGs for which the carrier is believed to have secured discounts well in excess of $50 \%$ over list prices" 7 . 
The LNG turboprop fuel cost advantage is 3 times the size of Bombardier CS100 so the consequences will not directly translate into the turboprop market, but, this quote does show that competitors can compete against a new entrant with aircraft pricing changes. Additionally, manufacturers selling older aircraft typically give discounts from published prices that are used in Figure 2. One analysis of the financial statements of Boeing and Airbus showed that these discounts can average as much as $35 \%$ and be as large as $50 \%{ }^{10}$ on programs that were $10-15$ years old. However, airline customers typically pay the manufacturer in installments during the time between the order and delivery which can be 2-5 years and this can affect the perceived discount if the manufactures take credit for the order cash flow during each installment instead of at the final delivery time.

The LNG aircraft manufacturer can also compete on price as the manufacturing cost of each new unit goes downknown as the "learning curve affect". Estimated manufacturing costs by manufacturing unit are shown in Figure 3. The purchase price for each LNG aircraft is shown to be between $\$ 40-\$ 48$ million dollars for 90 passengers in Figure 2. The manufacturing cost reaches $1 / 2$ of 48 million dollars at the end of the learning curve (unit 700). At this point, the LNG aircraft manufacturer could offer similar 50\% pricing discounts and remain profitable but this would not be possible until approximately year 10 of manufacturing (year 18 of the program) while other manufacturers are currently well past year 10 of older programs. A new entrant, or a derivative aircraft with new engines would also have to wait until year 10 to offer similarly sized discounts. However, a derivative aircraft would likely be sold at a larger discount, earlier in production due to the knowledge and low cost obtained in producing parts that are common to the previous "parent" aircraft. Despite strong competitive forces from manufacturers, the LNG turbroprop aircraft can still be profitable if the right combination of market share and profit margin can be obtained, and enough airlines demand 90 seat turboprops to uphold a market size of 1340 aircraft instead of settling for smaller, existing aircraft. A list of possible profitability outcomes is discussed in the next section.

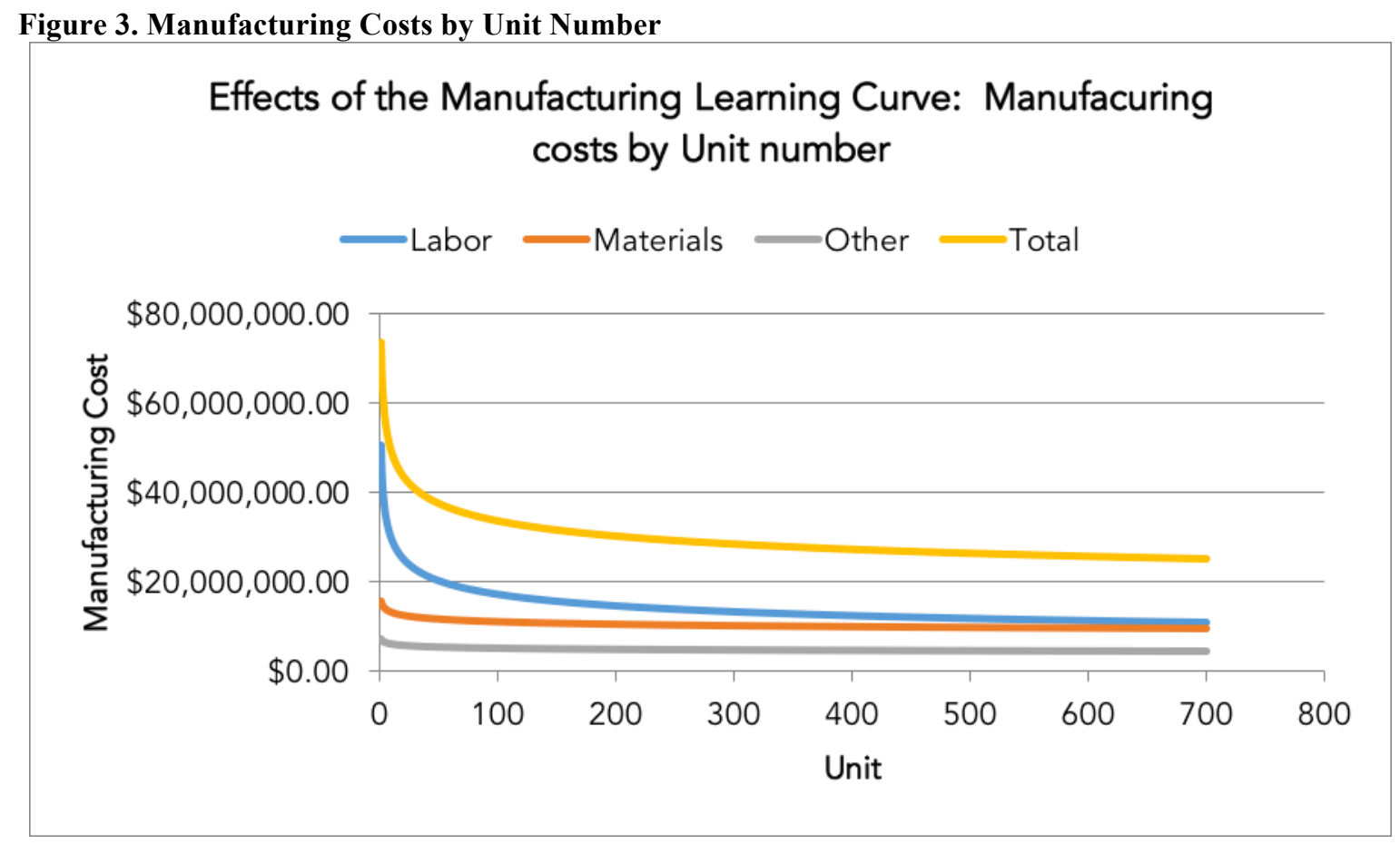

The LNG turboprop will have a competitive operating cost advantage due to the ability to set the price of LNG and the use of new engines (50-65\% lower fuel cost, 15\% lower engine related maintenance costs) in the turboprop market but the acquisition cost will likely be above the acquisition cost of existing and future aircraft of the same size which would offset some of the benefits. Figure 4 shows an estimated cost breakdown for short aircraft routes in Europe. This chart can be used to estimate the overall operating cost advantages from discounts in fuel cost, acquisitions, and other operating costs. 
Figure 4. Estimated Aircraft Operating Cost Breakdown for European Airline Operations

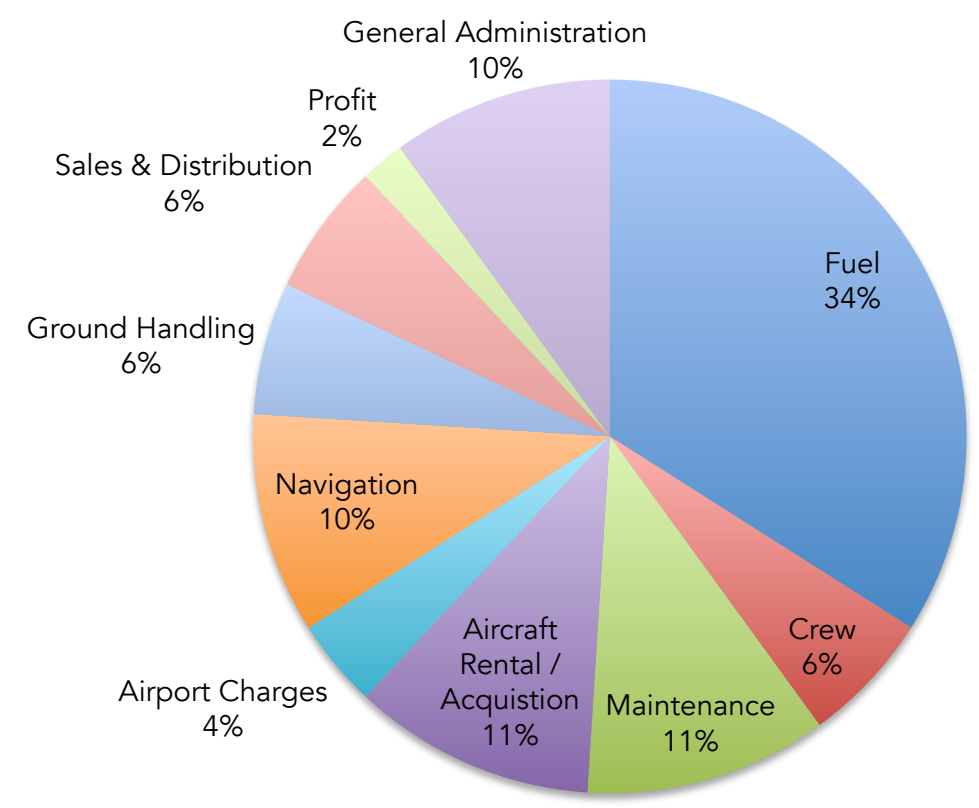

The lower fuel cost and maintenance costs that an LNG aircraft can offer add up to approximately $18-23 \%$ operating cost advantage (17-22.1\% overall from a $50-65 \%$ fuel cost discount, and $0.6 \%$ from a $15 \%$ engine related maintenance cost discount, (engine maintenance accounts for $4 \%$ of overall operating costs). Approximately half of this advantage $(8.9 \%)$ is returned to the manufacturer in the form of a higher acquisition price after financing, leading to a nominal operating cost advantage of between $9 \%$ and $14 \%$ for the LNG aircraft with a $5.7 \%$ manufacturing profit margin. Competitors can compete against the LNG operating cost advantage with pricing discounts as large as $50 \%$ (of ownership costs) on older jet fueled turboprops which would equal $5 \%-6 \%$ of total operating costs, although this would still be roughly half of the LNG cost savings which includes LNG manufacturer's profit margin. In the case that an airline were given an aircraft for at no cost, they would only save $11 \%$, roughly inline with the potential LNG savings. Thus, LNG turboprops will have robust overall cost advantages over older, existing turboprops even though they may be cheaper to acquire.

In the case that airlines will only replace existing aircraft with a 90 seat turboprop (essentially the incumbent aircraft are no longer competitors because they don't have a large enough seat capacity) and that replacement market is indeed 1340 aircraft, a new derivative aircraft with new engines would be the appropriate competitor for comparison (Perhaps a Bombardier Q400 derivative). In this case, the acquisition price for the derivative aircraft would be 20$30 \%$ lower than the LNG turboprop instead of $50 \%$, but with $15 \%$ lower fuel consumption than the older incumbent aircraft—or in terms of the pie chart, a $15 \%$ savings of fuel with virtually no increase in purchase price (a conservative estimate to make the business case harder for LNG aircraft). The total operating cost advantage over the older incumbent jet fueled turboprops would be $5.1 \%$ (from the fuel cost discount) roughly half to one third the advantage of the new LNG turboprop with new engines (9-15\%). In this scenario, the LNG turboprop would still have double to triple the overall cost savings over the potential future competitor and would likely achieve a $50 \%$ $75 \%$ market share split against the new derivative aircraft. The total comparative operating costs savings of future potential solutions relative to existing turboprops are shown in table Table 2. The estimated operating cost advantage of the LNG turbroprop relative to future competitive responses and current turboprops is shown in Table 3 .

Figure 5 shows the operating cost differences by category and the influence each category has on overall operating costs. The ownership costs difference $(26 \%)$ is greater than the development cost difference $(17 \%)$ due to costs associated with financing the aircraft purchase at $8.5 \%$ over 20 years. 
Table 2. Comparison of Operating Cost Reductions of Potential Turboprop Solutions Relative to Incumbent Turboprops

\section{Operating Cost Reductions relative to Incumbent Turboprops (Q400 \& ATR 72)}

\begin{tabular}{l|l|l|l} 
Older jet fueled turboprops & New Q400 derivative Jet fuel & New LNG Turboprop
\end{tabular}

with acquisition price Turboprop

discounts

\begin{tabular}{l|l|l}
\hline $5 \%-6 \%$ & $5.1 \%$ & $9 \%-15 \%$ \\
\hline
\end{tabular}

Other factors that could offset this balance include the introduction of carbon taxes (which would favor LNG aircraft) the cost of training pilots on a new aircraft type in cockpit (which would favor the derivative aircraft), or the desire for higher profit margins. The training cost advantage can be mitigated in part if LNG Turboprop manufacturer were an existing turboprop manufacturer and used the same cockpit as the previous aircraft with minor upgrades.

Table 3: Comparison of operating cost reductions of LNG turboprops relative to likely competitive responses

\section{Operating Cost Advantages of a new LNG turboprop relative to future competitors}

Older jet fueled turboprops New Q400 derivative Jet fuel Current Turboprops

with acquisition price Turboprop

discounts

$3 \%-11 \%$

$4.9 \%-8.9 \%$

$9 \%-15 \%$ 
Figure 5: Depiction of how LNG turboprop fuel, ownership, and maintenance cost differences translate to overall operating cost differences. In this example the cost differences from each category result in an overall 14.86 operating cost advantage vs. an existing turboprop.

\section{LNG Operating Cost Difference Breakdown Example: Net 14.86\% Overall Operating Costs Savings with 5.7\% Manufacturing Margin}
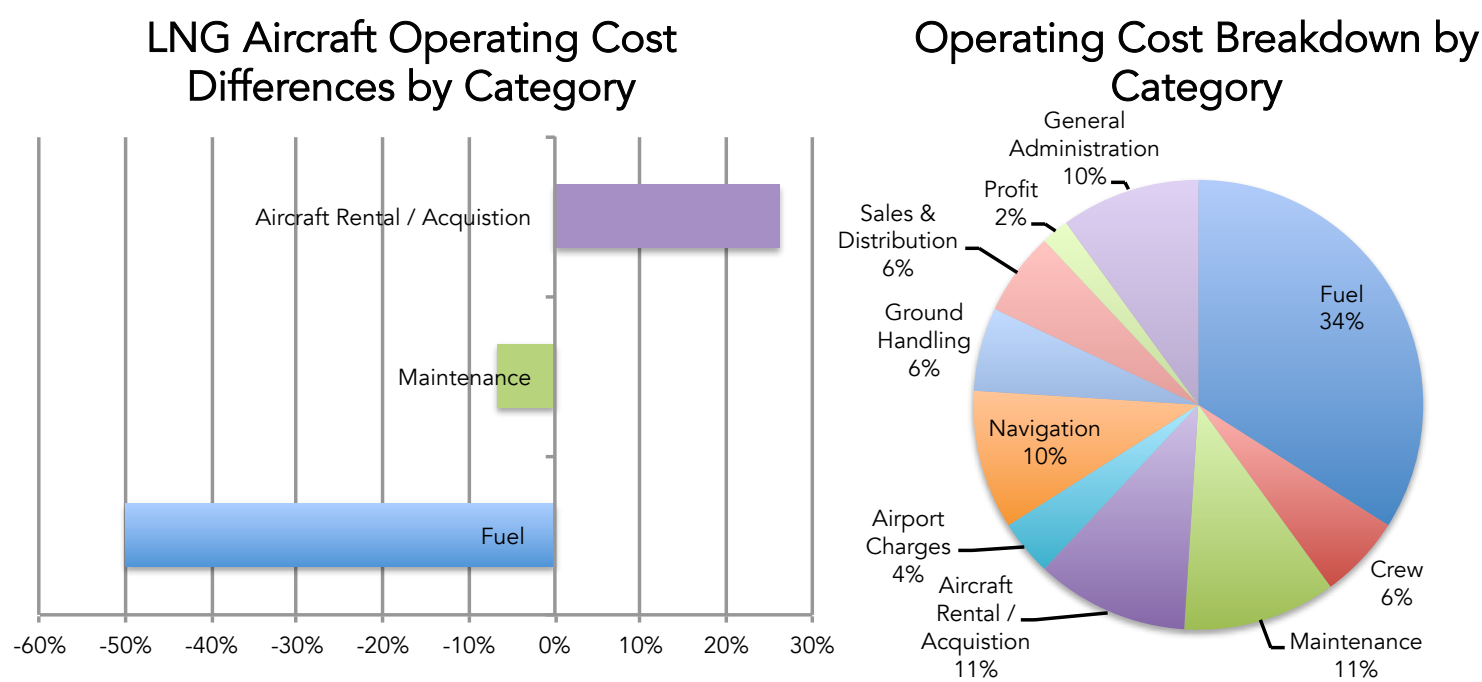

\section{Manufacturing Profitability}

The turboprop aircraft program profitability (includes all program costs including development, certification and manufacturing), and internal rates of return (IRR) implications for different manufacturing profit margins and associated market shares are shown in Table 4 and Table 5. The internal rates of return are computed from discounted cashflows described in the next section. The left column in both tables represents possible manufacturing profit margins, or, the revenue received the above the average manufacturing cost per aircraft. The ownership costs in are equal to the manufacturing revenue plus the financing costs for an $8.5 \%$ interest rate that the airline would incur.

Figure 6 is a comparison of program cash flows for an LNG turboprop under two different achieved market share scenarios, 23\% (unprofitable) and 47\% (profitable, 9.3\% IRR). The R\&D/Certification period is assumed to be 8 years long ( 7 years planned, 1 year delay). Both scenarios also show negative cash flow in year 9 , the first year of deliveries because the first aircraft manufacturing costs are higher than the purchase price due from starting at the beginning of the manufacturing learning curve. 
Table 4: Undiscounted profitability after 20 years (\$2.4 Billion initial investment required)

\begin{tabular}{|c|c|c|c|}
\hline \multirow{2}{*}{$\begin{array}{c}\text { Un-discounted } \\
\text { profits } \\
\text { Manufacturing Profit } \\
\text { Margin }\end{array}$} & \multicolumn{3}{|c|}{ Total \# of Aircraft Built, Maximum Build Rates, Resulting Market Share } \\
\hline & $\begin{array}{l}316 \text { aircraft, } 2.5 \\
\text { aircraft per month: } \\
24 \% \text { market share }\end{array}$ & $\begin{array}{l}630 \text { aircraft, } 5 \text { aircraft } \\
\text { per month, } \\
47 \% \text { market share }\end{array}$ & $\begin{array}{l}1005 \text { aircraft, } 8.3 \\
\text { aircraft per month, } \\
75 \% \text { market share }\end{array}$ \\
\hline $\begin{array}{l}5.7 \% \text { mfr margin (50- } \\
50 \text { split of cost saving } \\
\text { benefits between } \\
\text { manufacturer and airline) }\end{array}$ & Not Profitable & $\$ 4,265,524,201.87$ & $\$ 7,818,669,957.21$ \\
\hline $20 \% \mathrm{mfr}$ margin & $\$ 1,546,367,252.71$ & $\$ 7,729,047,300.75$ & $\$ 13,591,208,455.33$ \\
\hline $\begin{array}{l}25 \% \mathrm{mfr} \text { margin } \\
\text { (maximum for positive } \\
\text { airline ROI) }\end{array}$ & $\$ 2,153,800,541.22$ & $\$ 8,940,069,363.29$ & $\$ 15,609,578,559.57$ \\
\hline
\end{tabular}

Table 5: 20 year internal rates of return (IRR) on capital for various market penetration and manufacturing profit margin scenarios for an LNG turboprop aircraft development and manufacturing program.

\begin{tabular}{|c|c|c|c|}
\hline Internal Rate of Return & \multicolumn{3}{|c|}{ Market Share, Total \# of Aircraft Built \& Maximum Build Rates } \\
\hline $\begin{array}{c}\text { Grid } \\
\text { Manufacturing Profit } \\
\text { Margin }\end{array}$ & $\begin{array}{l}316 \text { aircraft, } 2.5 \\
\text { aircraft per month: } \\
24 \% \text { market share }\end{array}$ & $\begin{array}{l}630 \text { aircraft, } 5 \text { aircraft } \\
\text { per month, } \\
47 \% \text { market share }\end{array}$ & $\begin{array}{l}1005 \text { aircraft, } 8.3 \\
\text { aircraft per month, } \\
75 \% \text { market share }\end{array}$ \\
\hline $\begin{array}{l}5.7 \% \text { mfr margin (50- } \\
50 \text { split of cost saving } \\
\text { benefits between } \\
\text { manufacturer and airline) }\end{array}$ & Not Profitable & $9.3 \%$ & $17.1 \%$ \\
\hline $20 \% \mathrm{mfr}$ margin & $4.5 \%$ & $14.0 \%$ & $21.8 \%$ \\
\hline $\begin{array}{ll}25 \% \quad \mathrm{mfr} & \text { margin } \\
\text { (maximum for } & \text { positive } \\
\text { airline } & \text { ROI) }\end{array}$ & $5.9 \%$ & $15.4 \%$ & $23.2 \%$ \\
\hline
\end{tabular}


Figure 6. LNG turboprop program cashflows for various market shares

\section{LNG Turboprop Cashflow: 316 Aircraft, 30 aircraft per year, 24\% market share, $5.7 \%$ mfr margin}

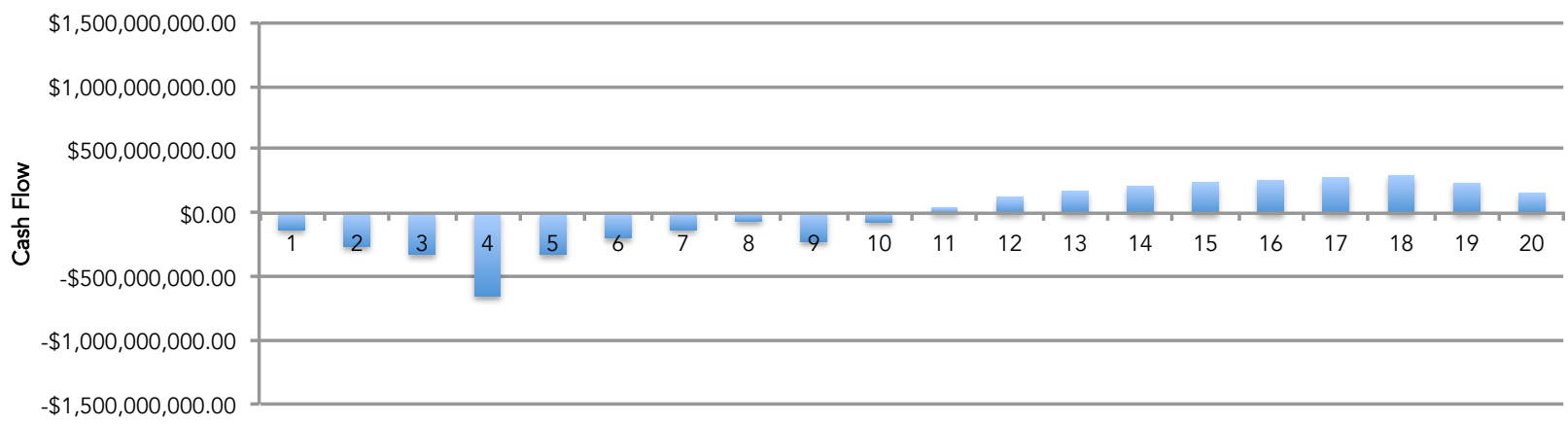

\section{LNG Turboprop Cashflow: 630 Aircraft, 60 aircraft per year, 47\% market share, $5.7 \% \mathrm{mfr}$ margin}

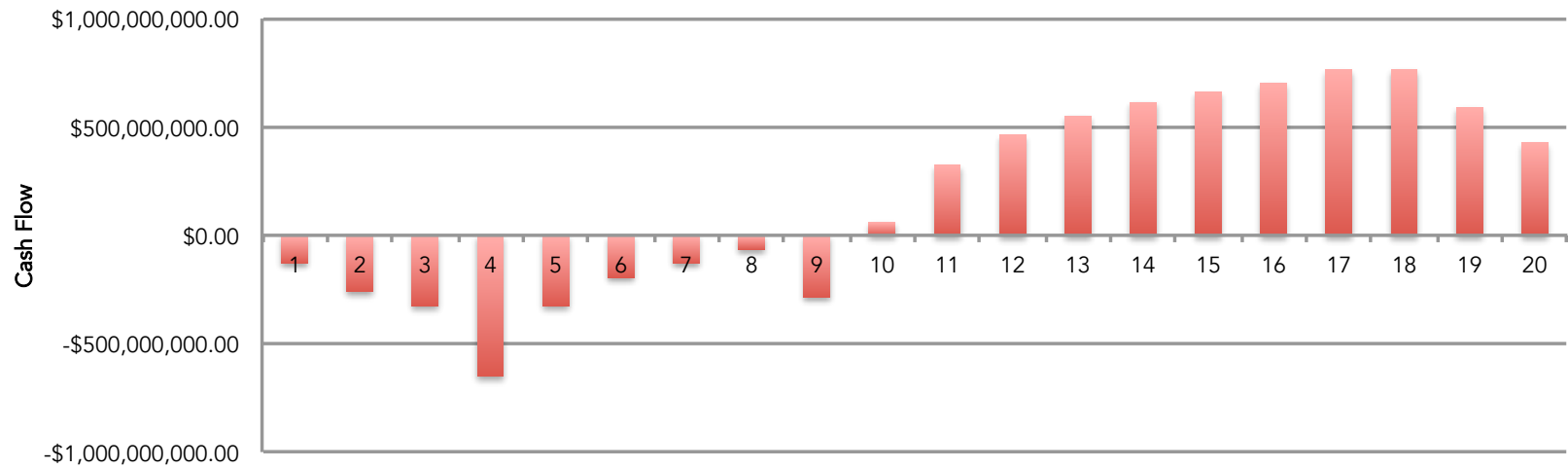

Profitability Assumptions:

- 20 year program life time

- We do not factor in returns or upfront costs from selling fuel, leasing aircraft, or selling maintenance services.

- 7 year development and certification program and a 1 year delay with revenues from sales beginning in year 8.

- A ramp up period for the first and first and second years of manufacturing (time to reach full speed manufacturing), the full manufacturing rate listed in the table would not be reached until year 3 of production (year 11 of the program).

- A slow down in manufacturing rate (ramp down period) is assumed for years 19 and 20 of the program

- Manufacturing learning curve rates were estimated at $85 \%$ for labor, $95 \%$ for materials, and $95 \%$ for other expenses respectively.

- $\mathrm{R} \& \mathrm{D}$ and certification costs were computed by assuming a $26 \%$ use of composites (for the new fuselage design and for the aircraft empennage), a 40,000 lb empty weight, a Mach .55 cruise speed, a 10-20\% increased design effort for LNG fuselage and fuel system, and a new upcoming turboprop engine from $\mathrm{GE}^{9}$ or Pratt \& Whitney ${ }^{10}$ would be selected and retrofitted.

- The R\&D and manufacturing cost and cash flow model is based on regression equations computed by Raymer and the Rand Corporation ${ }^{11}$ from data on many previous US military aircraft programs and 
corrected with cash flow and manufacturing data from Boeing described by Markish ${ }^{1}$ and inflation factors supplied by NASA.

- Our cost model predicts a $\$ 2.084$ billion development cost for a, jet fueled turboprop of the same size, in line with the $\$ 2$ billion dollar estimate made public statements made by ATR, the market leader in commercial turboprops over 60 seats on the cost of a new design ${ }^{3}$. ATR is a joint venture based in France which is $50 \%$ owned by Airbus, $50 \%$ owned by Alenia Aermacchi

\section{Conclusion}

The data shows there are many scenarios (combinations of achieved manufacturing profit margin and market share) which lead to profitability and a positive internal rate of return. The most likely scenario (discussed in the "Pricing Pressure from Competing Aircraft" section) would result in close to a 50-75 market share with a 5.7\% manufacturing profit margin. This scenario would net a $\$ 4.2-\$ 7.8$ billion dollar profit and a $9.3 \%-17.1 \%$ internal rate of return. A $24 \%$ market share is possible if enough airlines decide not to risk adopting a new LNG aircraft or large parts of the market are consumed by new entrants. The best chance to increase manufacturing margin would be to sell to airlines that are subject to carbon taxes which would effectively increase the operating cost advantage of LNG aircraft relative to jet fueled aircraft. Carbon taxes are currently implemented for all European Union (EU) flights and ICAO has plans for a global carbon tax, however global carbon taxes have often received pushback from airlines and been successfully defeated in the past. Rises in crude and/or jet fuel prices could also increase manufacturing margins but we have based our analysis assuming that the LNG will be sold at $50 \%$ the price of jet fuel.

\section{References}

${ }^{1}$ Perrett, B., "Five Manufacturers Proposing 90-Seat Turboprops" http://aviationweek.com/awin/five-manufacturers-proposing90-seat-turboprops, Aviation Week, August 5th 2013

${ }^{2}$ Moll, N., "With SSBJ, Aerion looks to revive supersonic flight" http://www.ainonline.com/aviation-news/ebace-conventionnews/2010-04-28/ssbj-aerion-looks-revive-supersonic-flight, AINonline April $28^{\text {th }} 2010$

${ }^{3}$ ATR Aircraft http://www.atraircraft.com/newsroom/news-events.html

${ }^{4}$ Bombardier:http://www.bombardier.com/content/dam/Websites/bombardiercom/supporting-documents/BA/BombardierAerospace-20140630-Q-Series-Program-Status-en.pdf

${ }^{5}$ Commercial Aviation Costs and Major Factors Influencing Infrastructure Changes at U.S. Airports to Accommodate the New A380 Aircraft, US Government Accountability Office, May 2006

${ }^{6}$ Aviation Week: Bombardier Says CSeries First Flight Will Boost Sales, March $18^{\text {th }} 2013$.

http://aviationweek.com/awin/bombardier-says-cseries-first-flight-will-boost-sales

${ }^{7}$ Flight Global: Analysis: Lessors spurn CSeries Overtures, April $4^{\text {th }} 2012$.

${ }^{8}$ J. Morrison, "Game Theory Analysis of Aircraft Manufacturer Innovation Strategies in the Face of Increasing Airline Fuel Costs". P.76 Report No: ICAT-2011-4, June 2011, Massachusetts Institute of Technology

${ }^{9}$ Alcok, C., "P\&WC Preapres aer Momentu Builds for New-Gen Turboprop" http://www.ainonline.com/aviation-news/dubai-airshow/2013-11-16/pwc-prepares-momentum-builds-new-gen-turboprop, AINonline, November 16, 2013

${ }^{10}$ Raymer, D, Aircraft Design: “A Conceptual Approach: Reston American Institute of Aeronautics and Astronautics”

${ }^{11}$ Markish, J. "Valuation Techniques for Commercial Aircraft Program Design", Master's Thesiss- Massachusetts Institute of Technology, Cambridge MA 2002 